Costa, Hermes Augusto, Sindicalismo global ou metáfora adiada? Discursos e práticas transnacionais da CGTP e da CUT.

\title{
Olinda Lousã
}

\section{OpenEdition}

\section{Journals}

Edição electrónica

URL: http://journals.openedition.org/rccs/206

DOI: $10.4000 /$ rccs.206

ISSN: 2182-7435

Editora

Centro de Estudos Sociais da Universidade de Coimbra

\section{Edição impressa}

Data de publição: 1 setembro 2009

Paginação: 171-175

ISSN: 0254-1106

\section{Refêrencia eletrónica}

Olinda Lousã, « Costa, Hermes Augusto, Sindicalismo global ou metáfora adiada? Discursos e práticas transnacionais da CGTP e da CUT. », Revista Crítica de Ciências Sociais [Online], 86 | 2009, posto online no dia 01 outubro 2012, consultado o 21 setembro 2020. URL : http://journals.openedition.org/rccs/206 ; DOI : https://doi.org/10.4000/rccs.206 


\section{Recensões}

\section{Poddar, Prem; Patke, Rajeev S.; Jensen, Lars (orgs.) (2008), A Historical Companion to Postcolonial Literatures. Continental Europe and Its Empires. Edinburgh: Edinburgh University Press, 633 pp.}

O volume em apreço vem na sequência de uma colectânea anterior, $A$ Historical Companion to Postcolonial Literatures in English, da responsabilidade de Prem Poddar e David Johnson, publicada em 2005 também pela Edinburgh University Press. Trata-se, neste segundo volume, da abordagem da história colonial da "Europa continental" e da análise dos contextos pós-coloniais dela decorrentes. São, assim, oferecidos capítulos sobre a Bélgica, a Dinamarca, a França, a Alemanha, a Itália, os Países Baixos, Portugal e Espanha, bem como um pequeno excurso sobre as "outras Europas" (com breves ensaios sobre o conceito de "choque de civilizações", sobre a diáspora judaica e sobre a Rússia, a Suécia e a Turquia). Todos os capítulos, organizados na forma de um conjunto de verbetes, obedecem à mesma matriz, adaptada, conforme os casos, às exigências concretas do contexto específico.

$\mathrm{O}$ que se exige deste género de obras de referência é um levantamento informativo, sintético, tanto quanto possível exaustivo, de um determinado campo de investigação. Este Historical Companion cumpre, indubitavelmente, essa função: o resultado final oferece uma imagem rica e diferenciada, que proporciona ao leitor interessado diferentes vias de acesso e abre um amplo caminho a uma leitura comparativa e transversal, uma vez que permite sublinhar a dimensão transnacional e transcultural dos contextos históricos que analisa. No conjunto, a obra satisfaz plenamente a pretensão formulada pelos organizadores, na sua introdução geral, de vir a constituir um instrumento útil "para fundar os estudos pós-coloniais numa consciência histórica e fundar a consciência histórica do colonialismo moderno e do impacto que continua a exercer nas realidades contemporâneas num contexto comparativo assente na noção da dimensão literária da historicidade da experiência” (2).

A teoria pós-colonial esteve dominada durante muito tempo por um modelo anglo-saxónico que subsumia a especificidade das diferentes experiências coloniais e pós-coloniais num único sistema de referências. A investigação mais recente, em contrapartida, não só tem vindo crescentemente a acentuar a polissemia e pluralidade do conceito de "pós-colonialismo", mas também a impossibilidade de entender esse conceito independentemente dos contextos específicos a que se refere. A percepção de que o colonialismo não foi um processo uniforme e de que diferentes histórias coloniais tinham necessariamente que gerar contextos pós-coloniais também diversos tornou-se entretanto consensual. Investigadores ibéricos e latino-americanos como Boaventura de Sousa Santos, Enrique Dussel, Aníbal Quijano ou Walter Mignolo têm vindo a contribuir de modo decisivo para uma perspectiva mais diferenciada. Mas também a atenção crescente a domínios até aqui subalternizados, como a história colonial alemã ou o colonialismo intra-europeu (que o presente volume, diga-se, deixa inteiramente de lado) tem vindo a aguçar o olhar para a pluralidade do problema.

O primeiro grande mérito da obra em análise está em fazer justiça a esta pluralidade 
através do tratamento em profundidade dos casos relevantes na Europa, incluindo casos aparentemente marginais, como, por exemplo, a história colonial da Dinamarca. $\mathrm{O}$ trabalho não se detém na questão, em última análise paralisante, de uma definição acabada do pós-colonialismo, debruça-se, em vez disso, de modo concentrado, sobre os contextos históricos concretos e procura chegar, a partir deles, a uma delimitação das questões relevantes para cada um desses contextos. Cada capítulo abre com uma breve introdução do seu responsável e organiza-se em verbetes que abrangem os campos mais importantes em cada caso. É naturalmente discutível se, aqui ou ali, a escolha dos temas não poderia ter uma configuração diferente, mas, no conjunto, pode dizer-se que estão contempladas as questões essencialmente relevantes. Os múltiplos cruzamentos entre os diferentes verbetes são claramente sublinhados - através também da ocorrência nos vários capítulos dos mesmos conceitos centrais, como Crioulização, Orientalismo, Migrações, Raça e Etnicidade, Histórias de Mulheres, etc. -, de modo que não chega a gerar-se a impressão do fragmentário ou do simples alinhamento enciclopédico de conceitos isolados. Mesmo assim, teria, sem dúvida, sido desejável que as introduções aos vários capítulos (tal como, aliás, a introdução geral dos organizadores) não tivessem uma forma tão sucinta.

Um segundo mérito desta obra que importa sublinhar consiste na abordagem das relações entre as metrópoles e a suas colónias não na forma de um simples contraste binário, mas, pelo contrário, na forma de uma relação complexa de interdependência mútua. Isto é, colonizador e colonizado são pensados como parte de um mesmo campo analítico: a colonização não é apresentada como um processo que se desenrola à distância e em cujo decurso uma metrópole aparentemente inalterada se confronta com um Outro exterior, mas como uma transformação profunda, que revoluciona completamente os territórios e as populaç̃os colonizados, mas de nenhum modo deixa intocada a potência colonial. Pode, assim, ser adequadamente tematizada a imbricação inextricável entre colonialismo e modernidade e os aspectos abordados tornam-se analisáveis de forma mais clara como parte de uma história do presente. Um terceiro aspecto deste Historical Companion que merece realce diz respeito ao olhar crítico que subjaz à maioria dos contributos. Idealizações correntes são mantidas à distância e mitos históricos estabelecidos são submetidos a uma revisão impiedosa. Através da presença constante de temas como a escravatura, sublinha-se a concepção do colonialismo como o lado sombrio da modernidade. A noção de que a relação colonial é necessariamente uma relação de violência, situa-se, aliás, no centro da análise, o que permite correcções decisivas a historiografias nacionais ainda hoje vigentes e fornece, por sua vez, as bases necessárias para uma compreensão dos contextos pós-coloniais.

Poderia perguntar-se, em quarto e último lugar: e onde fica a literatura? O volume está concebido como "Historical Companion”, pelo que não seria, naturalmente, de esperar um tratamento exaustivo da dimensão literária. Do que se trata, em primeira linha, é de uma abordagem dos aspectos históricos que permitem uma contextualização adequada dos processos literários nos espaços coloniais e pós-coloniais. Ao longo dos diferentes capítulos, esses aspectos vão sendo postos em relação com os problemas literários relevantes. Teria sido desejável mais algum pormenor em vários momentos, mas tem de reconhecer-se que a obra cumpre à saciedade a sua função principal de contextualização sem pôr em causa a posição e o significado específico da literatura. 
Não sendo, naturalmente, possível, no âmbito desta recensão, comentar em pormenor os vários capítulos, concentrar-me-ei seguidamente, a título exemplar, nos casos da Alemanha e de Portugal

Como é sublinhado pela responsável por este capítulo, Birthe Kundrus, a historiografia alemã concedia tradicionalmente apenas um lugar absolutamente secundário à questão do colonialismo, só em anos recentes se tendo registado quase uma explosão do interesse por esta temática. É com base nos resultados dessa investigação mais recente - de que a responsável pelo capítulo é uma das mais proeminentes representantes - que se estrutura a abordagem proposta. O pressuposto essencial é que, embora a breve história colonial alemã se tenha encerrado em definitivo em 1918, a relação colonial tem também neste caso um significado marcante. É neste sentido que Birthe Kundrus defende com veemência - e com toda a justeza - que a sociedade alemã, tal como a britânica ou a francesa, deve ser vista como uma sociedade pós-colonial (203).

A estrutura do capítulo é muito equilibrada, com um conjunto de verbetes muito informativos e representativos do estado mais avançado da investigação. Alguns subcapítulos, como, por exemplo, "African playground”, que se debruça sobre o uso muito difundido de jogos para crianças ou jogos de sociedade com temática colonial, são de grande originalidade e oferecem pistas de investigação que seriam de muito interesse também relativamente a outros contextos nacionais. A organizadora chama a atenção para o facto de que, no âmbito da investigação sobre a história colonial alemã, muito está ainda em aberto e que, em múltiplos campos, não existem ainda resultados definitivamente estabelecidos (201). Mas isto aplica-se também, ainda que não necessariamente pelos mesmos motivos, nos casos de outros países, em que as perspectivas pós-coloniais mais recentes puseram muita coisa em movimento e levaram, em muitos aspectos, a uma revisão de princípios anteriormente aceites. E o caso alemão, por exemplo com a pergunta inteiramente em aberto sobre a relação entre a violência colonial e a política genocida do nacional-socialismo ou com as especificidades das práticas da memória e das políticas da memória, suscita problemas que podem trazer um contributo novo e essencial para a reflexão geral. Uma única grande lacuna tem de ser assinalada, o facto de o espaço de língua alemã não ser analisado no seu conjunto, isto é, com inclusão do Império Austro-Húngaro. $\mathrm{Na}$ verdade, a ausência da Áustria, que, como revela a consulta do útil índice de assuntos, não chega nunca a ser mencionada em todo o volume, é causa de estranheza, tanto mais quanto neste capítulo há referências ocasionais a aspectos austríacos sem um reconhecimento do seu lugar específico (como, por exemplo, quando o arquitecto e crítico da cultura vienense Adolfo Loos surge referido como "German writer” [230]). É verdade que, diferentemente do Reich alemão, a monarquia habsbúrgica nunca possuiu colónias ultramarinas e nunca esteve em posição de as reivindicar; apesar disso, como Walter Sauer demonstrou convincentemente (cf. Walter Sauer [org.], K.u.k. kolonial. Habsburgermonarchie und europäische Herrschaft in Afrika. Wien: Böhlau, 2002), a questão colonial possui um significado marcante também para a Áustria. Acresce o importante aspecto do colonialismo intra-europeu, nomeadamente nos Balcãs, expresso em particular na ocupação e anexação da Bósnia-Herzegovina e que constitui um capítulo da história colonial europeia que não pode ser ignorado. De facto, em anos recentes, a investigação tem podido demonstrar com crescente clareza que também no caso austríaco a questão 
do colonialismo e do pós-colonialismo tem um significado marcante.

No caso português, parece evidente que uma história colonial que se estendeu por mais de quinhentos anos suscita em vários aspectos questões específicas e de grande complexidade. É, pois, muito de lamentar que o capítulo sobre Portugal, da responsabilidade de Phillip Rothwell, tenha uma qualidade claramente inferior à que é regra no conjunto do volume. $\mathrm{Na}$ verdade, ao lado de contributos excelentes, como, por exemplo, entre vários, "Lusotropicalism, Race and Ethnicity", por Anna Klobucka, ou "Women's Histories in the Lusophone Colonial and Postcolonial Worlds", por Hilary Owen, outros há que deixam francamente a desejar.

Em vários casos, não parece haver sequer domínio do estado actual da investigação, como revela o facto de o subcapítulo "Explorations and Discoveries" recomendar a obra $A$ History of the Portuguese Discoveries, de Damião Peres, como ainda hoje actual e "extremamente abrangente e legível” (446). Na verdade, trata-se, como é sabido, de uma obra publicada em 1960 no âmbito das comemorações henriquinas e que mais não representa do que uma síntese em inglês, de pouco mais de cem páginas, dos trabalhos do autor sobre a expansão portuguesa, trabalhos estes de tónica marcadamente nacionalista. Quando se verifica que o verbete em causa ignora olimpicamente uma obra fundamental como a História da Expansão Portuguesa, organizada por Francisco Bethencourt e Kirti Chaudhuri para o Círculo de Leitores em 1998, não se pode senão ficar perplexo. A única explicação será o facto de neste verbete, como em vários outros, parecer ter sido seguido o princípio de só ter em consideração referências em língua inglesa. Trata-se, como é bom de ver, de um critério mais do que problemático, que terá necessariamente de deixar de fora referên- cias fundamentais. E não deixa de chamar a atenção que este critério não seja, evidentemente, aplicado nos casos francês ou alemão, mas não pareça ter suscitado dúvidas ao responsável do capítulo sobre Portugal que, aliás, no verbete "Historiography", de sua autoria, depois de uma apresentação sumária, basicamente pertinente, da historiografia portuguesa até ao final do século XIX, julga, num brevíssimo parágrafo final, dever cingir-se a "historiadores de Portugal em língua inglesa" (459). Esta estranhíssima limitação não apenas obriga a silenciar também neste caso os cinco volumes de Bethencourt e Chaudhuri, mas faz também com que, para me restringir a um único exemplo, a obra fundamental de um Vitorino Magalhães Godinho não mereça sequer menção (apesar de alguns textos de Godinho estarem disponíveis em versão inglesa ou francesa).

Muitas outras observações críticas poderiam fazer-se. Há conceitos fundamentais que não são tratados, como, por exemplo, o de lusofonia (apesar de no capítulo sobre a França surgir o verbete "Francophone"). A questão da cultura material e da memória monumental ou museológica, tal como, em geral, a questão, por exemplo, da arquitectura de influência portuguesa, teriam merecido imperativamente um tratamento próprio adequado. É inexplicável que o tema fundamental das migrações pós-coloniais com origem nas antigas colónias africanas seja tratado apenas com respeito a Moçambique e não seja sujeito a um tratamento global - toda a importante questão da reconfiguração de Portugal como sociedade pós-colonial multicultural tem, deste modo, de ficar basicamente por tratar.

Alguns verbetes teriam de ser inteiramente reescritos para se situarem num patamar minimamente aceitável. É o caso do verbete "The Carnation Revolution", que não apenas se fica à superfície dos acontecimentos, por vezes num plano simplesmente 
anedótico, como contém também imprecisões inaceitáveis, como a de se escrever que "um grupo de oficiais do exército [...] unido em torno das ideias de um general popular, António Spínola” (443) teria estado na origem da Revolução dos Cravos. Também o verbete "Moorish Portugal”, da mesma autora, Kathryn Bishop-Sanchez, corresponde ao que pode esperar-se de um vulgar guia turístico, mas não satisfaz minimamente qualquer critério de exigência científica. Também relativamente a este tema a investigação portuguesa dos últimos trinta anos, totalmente ignorada pela autora, tem dado contributos decisivos.

A utilidade deste capítulo surge, é forçoso concluir, muito prejudicada pela desigual qualidade das várias entradas e pela aplicação de critérios que são muito questionáveis, nomeadamente, repita-se, a opção, diferente da seguida noutros capítulos, de pri- vilegiar a investigação em língua inglesa, assim deixando de lado referências basilares. O volume conclui-se com um índice onomástico e um índice por assuntos, bem como com uma útil e informativa "Selective Chronology of Historical and Literary Events". Apesar dos aspectos que tiveram de merecer uma anotação crítica, a obra destaca-se pela sua qualidade, possui uma abrangência que, nesta forma, não estava ainda disponível no universo bibliográfico e irá, seguramente, afirmar-se durante muito tempo como uma referência imprescindível. Espera-se que em edições posteriores, que decerto irão ser necessárias, não se desperdice a oportunidade de actualizar o conjunto do volume e, em particular, de submeter a revisão os verbetes menos conseguidos, recorrendo aos especialistas reconhecidos das respectivas matérias.

\section{António Sousa Ribeiro}

\section{Costa, Hermes Augusto (2008), Sindicalismo global ou metáfora adiada? Discursos e práticas transnacionais da CGTP e da CUT. Porto: Edições Afrontamento, $347 \mathrm{pp}$.}

Sindicalismo global ou metáfora adiada? Discursos epráticas transnacionais da CGTP e da CUT é o resultado da tese de doutoramento em Sociologia de Hermes Augusto Costa, docente da Faculdade de Economia da Universidade de Coimbra e investigador do Centro de Estudos Sociais. O livro, organizado em 5 capítulos, reflecte um conjunto de experiências de investigação, desenvolvido ao longo de vários anos. A pesquisa, dedicada à procura de um "sindicalismo de língua portuguesa", dividiu-se entre Portugal e o Brasil, centrando-se em duas centrais sindicais, respectivamente CGTP e CUT.

A investigação interroga-se sobre a existência, contornos e eficácia de uma política de relações internacionais no seio do mo- vimento sindical, que sendo afirmada e almejada por dirigentes sindicais, fica contudo muito aquém da transnacionalização que a economia logrou alcançar.

Apesar das diferentes formas de actuação, condicionadas pelas respectivas condições locais de inserção, constata-se nesta pesquisa que as duas centrais sindicais - CGTP de Portugal e CUT do Brasil - encetam afinal um caminho na procura da transnacionalização, que não é nem tão directo nem tão rápido como o da globalização económica. Que foi o capital e não o trabalho que logrou internacionalizar-se é uma inegável evidência.

O autor traça um duplo diagnóstico, aparentemente antagónico, de crise e de pujança do movimento sindical. Apesar da exclusão 
social, do desemprego e do individualismo contemporâneo, o espaço do mundo do trabalho ainda não foi substituído por outra forma de organização da sociedade. O movimento sindical fragilizado está a recompor-se. Apesar dos muitos erros, o autor prefere salientar, pela positiva, os contributos e a actualidade desta forma de intervenção e transformação social, em tempo de globalização.

Os recursos metodológicos foram sobretudo entrevistas a dirigentes sindicais, quer das centrais sindicais em análise, quer de vários sindicatos. Encontramos também testemunhos através de outras entrevistas (jornais, revistas) que se interligam com o objecto deste trabalho. As pesquisas documentais na CGTP, na CUT, na Confederação Europeia de Sindicatos (CES, em Bruxelas) e na AFL-CIO (EUA) foram outro recurso utilizado.

Hermes Augusto Costa começa por analisar o impacto das transformações das últimas décadas na esfera laboral e as consequentes ondas de choque no movimento sindical. Identifica factores da crise nacional e transnacional que o sindicalismo atravessa. Avança com algumas propostas para a renovação do modo de fazer e estar dos actores sindicais com vista à ultrapassagem desses condicionalismos, chamando a atenção para o facto de todos os intervenientes envolvidos na globalização desenvolverem a sua actividade nos planos nacional, regional, internacional ou multinacional. Interroga-se sobre se há algum vestígio de política de relações internacionais na agenda do movimento sindical. Conseguirão os sindicatos globalizar a sua acção para resistir aos efeitos nefastos da globalização neoliberal? Os actores/dirigentes sindicais, em cada país, pensam, estudam, dialogam, anseiam por esse papel mobilizador? Estarão a tentar articular-se nos vários níveis regionais e transnacionais a fim de, em breve, poderem ver resultados da política de relações internacionais que estão, de forma melhor ou pior, a pôr em prática? Um dos desafios da construção de uma política de relações internacionais deriva da limitação de as organizações sindicais estarem mais vocacionadas para intervir no plano nacional. É aí que actuam regularmente, propondo melhorias salariais, monitorizando a aplicação de clausulados contratuais e denunciando ilegalidades. No entanto, há que rearticular organicamente e transnacionalizar estruturas. A filiação não é apenas um acto formal. Está em jogo uma institucionalização de procedimentos e práticas que poderá conferir ao sindicalismo aptidão para desafiar as estratégias do capitalismo global.

Neste domínio, refere-se o desafio das experiências de diálogo social transnacional, que podem ser maximizadas no quadro das $\mathrm{Em}$ presas Transnacionais (ETNs). Mais difícil de alcançar, mas mais aliciante e promissor, é o desafio da ligação a outros movimentos sociais e outros sectores da sociedade, bem como o uso das novas tecnologias. Quanto às duas centrais sindicais analisadas nesta obra, é feita uma apresentação das suas origens e uma análise das suas pretensões, concepções sindicais e linhas de actuação. Lembram-se os contributos que as duas organizações deram aos processos de democratização em Portugal e no Brasil, já que ambas nasceram em contextos de clandestinidade ou semi-clandestinidade, no período das ditaduras. Vinda de um sindicalismo de forte contestação, a CUT assume na actualidade uma postura em que a negociação ombreia com o conflito, sendo a sua base social menos classista do que a da CGTP e defendendo princípios similares aos da central portuguesa, incluindo um sindicalismo de massas com referência ao socialismo como meta. Ao longo do capítulo 2 são analisadas as fases marcantes da política de relações internacionais das duas centrais sindicais, 
através da análise de entrevistas e de documentos, procurando, à lupa, menções a vestígios dessa política.

Mostra-se que o financiamento se revela um travão a uma política de relações internacionais mais intensa. Como as duas centrais dão prioridade aos temas nacionais, também não sentem muita necessidade de uma política de relações internacionais. Quando muito, privilegiam as dinâmicas/os contactos regionais (da CES, no caso da CGTP, e do Mercosul, no caso da CUT). Ao nível internacional, a CUT aderiu à então CISL/ORIT, em 1991, enquanto a CGTP ainda não aderiu à Confederação Sindical Internacional (CSI, criada em Novembro de 2006). Quer uma quer outra central sindical não deixam de levar a sua agenda progressista (paz, exclusões, trabalho digno, etc.) às instituições supranacionais em que estão filiadas.

O desafio das ligações orgânicas e a sua passagem de um plano nacional a um outro supranacional é abordado no capítulo 3. $\mathrm{O}$ autor lembra que este processo, via filiação, pressupõe uma "reconstituição dos sindicatos que funcionam, gradualmente, mais como redes do que como hierarquias". São abordados os motivos invocados pelas duas centrais para a filiação internacional, os obstáculos, polémicas e debates gerados, bem como as consequências da efectivação deste processo. Apesar da gradual aproximação às teses da CES, a CGTP não deixou de criticar sempre a dependência da CES relativamente à UE. Por seu turno, depois de um período de desconfiança e discussão, o movimento sindical brasileiro acedeu, a partir de 1996, à então Confederação Internacional dos Sindicatos Livres (CISL, que deu origem à actual CSI). São discutidas as semelhanças e diferenças entre os processos de filiação transnacional da CGTP e da CUT. No capítulo 4 tomamos conhecimento de experiências de participação laboral e de diálogo social, enquadradas nas empresas multinacionais - caso dos Conselhos de Empresa Europeus (CEEs) e do Contrato Colectivo Mercosul (CCM) na América Latina. Nos corredores e boardrooms das multinacionais há afinal uma possibilidade legal de ligar pontas, atar nós que ajudem à construção de redes de solidariedade transnacional, mesmo que de diferente conteúdo e alcance.

$\mathrm{Na}$ Europa, os CEEs resultam da Directiva 94/45/CE (substituída em 2009 pela Directiva 2009/38/CE), que instituiu o direito de informação e consulta dos trabalhadores nas empresas ou grupos empresariais de dimensão comunitária. Superar barreiras é o único caminho que parece ser possível encetar, criando condições de organização laboral transnacional, assentes numa articulação de lutas que resultam da partilha de problemas comuns, apesar das diferentes nacionalidades, línguas, culturas.

Várias similitudes dos CEEs e CCMs foram detectadas neste trabalho. Estes instrumentos permitem, em teoria (e este é afinal o seu calcanhar de Aquiles), uma vigilância dos acordos capital-trabalho transnacionais. As organizações de trabalhadores que anseiem internacionalizar-se pela negociação colectiva multinacional devem deixar de olhar as multinacionais como uma "caixa negra". Podem superar a falta de informações e de análise crítica através de relações com outras organizações congéneres, na mesma multinacional, noutros países. Saber onde produz a empresa, quanto pode oferecer, quais as vulnerabilidades e quais as estratégias de investimento (localizações/deslocalizações) são trunfos essenciais. O estudo identifica algumas semelhanças e diferenças entre os dois tipos de participação laboral, na Europa e no Brasil. Com o $5^{\circ}$ e último capítulo, Hermes Augusto Costa aponta um diagnóstico positivo para o movimento sindical, a partir das 
duas centrais estudadas, ainda que realce o facto de a alteração de culturas sindicais instaladas ser processo por vezes lento e até penoso. Isto porque os sindicatos operam nas áreas organizadas da sociedade, enquanto as ONGs se relacionam com sectores excluídos, com interacção informal com o Estado. Refere também a desconfiança do movimento sindical relativamente às ONGs, já que estas não têm representatividade aferível. Por isso, só uma abertura dos sindicatos, que tem de efectuar uma série de rupturas mais ou menos radicais, potenciará o sindicalismo como movimento societal bem sucedido, numa perspectiva internacionalista.

Um sindicalismo de movimento social representa, pois, um teste à capacidade de mudança do sindicalismo, sobressaindo de tal âmbito as resistências ao diálogo e participação com outras organizações da sociedade civil, descontextualizadas da acção sindical mais tradicional. Mas o autor sublinha a necessidade de a transnacionalização do movimento operário deixar de ser vista pelo movimento sindical como sinónimo, exclusivo, de transnacionalização do sindicalismo. Através das políticas de relações internacionais será possível expandir a esfera de acção para fora do estritamente sindical, dando corpo a um "sindicalismo cidadão", aberto ao exterior, que a CUT, no Brasil, melhor tem conseguido. Assim se abre, com efeito, a porta ao "novo sindicalismo social" - forma organizativa proposta por Peter Waterman - e apoiado em "novos movimentos sociais alternativos" e na prática de uma "solidariedade internacional em casa”, uma solidariedade ética, e no diálogo com intelectuais, especialistas e comunidades científicas, com interesses não estritamente sindicais.

A CGTP participou e comunga do espírito de Porto Alegre, afirmando pela voz do seu secretário-internacional: "Nós es- tamos neste movimento porque queremos transformar esta sociedade". Agir contra a corrente, agir para transformar, é um slogan constante da central sindical. Referindo-se à Internet, Hermes Augusto Costa enuncia este canal virtual como grande recurso ao dispor do sindicalismo no período do capitalismo globalizado. Com o exemplo de Eric Lee e a "sua" rede de trabalho global, estabelece uma comparação ao ideário marxista, onde já se perspectivava a maximização dos meios de comunicação da industrialização, que agora melhor se potenciará. A Internet e o $e$-sindicalismo podem ajudar a política de relações internacionais, dar força às possibilidades do sindicalismo de movimento social transnacional, ultrapassar as fronteiras espaciais, institucionais e de classe. Uma vez mais, o livro elenca semelhanças e diferenças entre a CGTP e a CUT quanto aos contributos para um sindicalismo de movimento social transnacional. $\mathrm{O}$ autor evidencia portanto, nesta pesquisa, a necessidade de o movimento sindical aprofundar as suas relações bilaterais e multilaterais, carência que os responsáveis admitem e procuram suprir. Identifica a política de relações internacionais adoptada pelo movimento sindical português (CGTP) e brasileiro (CUT) como uma vertente que tem o seu lugar cativo e determinante na estratégia destas organizações. É no desafiar das potencialidades destes possíveis laços internacionais que estará a solução para a tão ansiada renovação face à globalização do capital económico e financeiro. Algumas diferenças quanto ao exercício desta política pelas duas centrais derivam de problemas de escala geográfica, de ligações partidárias assumidas pela CUT e "escondidas" pela CGTP, de crítica em detrimento do diálogo (CGTP em relação à CES), de menos atenção da CGTP do que a CUT à formação sindical nestas temáticas. Destacam-se três grandes desafios associados à política de relações internacionais: a) a definição de 
estratégias que possam conduzir à inserção orgânica transnacional (seja regional ou mundial); b) as experiências em termos de participação laboral e de diálogo social enquadradas nas empresas multinacionais (CEEs e CCMs); c) a construção de um sindicalismo de movimento social transnacional. Tais desafios são, afinal, contributos válidos, ainda que parcelares, para um "sindicalismo global” que, ao que parece, não passa ainda de uma metáfora adiada.

Em resumo, este quase manual de sindicalismo é de grande utilidade para sindicalistas, trabalhadores, estudantes e académicos, enfim, para todos os leitores estudiosos, atendendo ao que traz de compilação (passado) e de novidade e actualidade (olhar para o presente e o futuro). A globalização está aí para o provar, a braços com uma vasta contestação ao modelo baseado nas leis de mercado, tendo os Estados sido chamados a intervir após o descalabro financeiro que emergiu nos finais de 2008, e ainda sem fim à vista.

\section{Olinda Lousã}

\section{Richmond, Oliver; Franks, Jason (2009), Liberal Peace Transitions: Between Statebuilding and Peacebuilding. Edinburgh: Edinburgh University Press, 230 pp.}

Em um mundo onde é cada vez mais premente uma melhor compreensão da conflitualidade internacional visando a sua transformação, mais urgente é talvez um olhar atento ao modo como se desenrola a construção da paz pelo globo. É precisamente neste espaço de debate que se insere a obra Liberal Peace Transitions - Between Statebuilding and Peacebuilding de Oliver Richmond e Jason Franks. O livro é o resultado de uma extensiva pesquisa de campo em cinco ambientes de conflitualidade violenta, objetivando a observação e compreensão do tipo de paz construída nestas localidades.

Ao buscar observar que paz está sendo construída na contemporaneidade, Richmond e Frank selecionam como estudos de caso o Camboja, a Bósnia, Timor Leste, o Kosovo e o Oriente Médio, sendo dedicado um capítulo da obra a cada localidade. Esta seleção busca precisamente uma representação cronológica dos projetos de construção da paz no período pós-Guerra Fria até 2007. É curiosa a escolha do Oriente
Médio enquanto estudo de caso, uma vez que este destoa bastante dos processos de construção da paz realizados em outras localidades, principalmente nos outros estudos de caso escolhidos pelos autores. Contudo, este é incluído justamente com o intuito de observar a construção da paz em uma localidade onde as Nações Unidas, ator chave na construção da paz liberal para os autores, não possui grande acesso e, assim, refletir em que medida a grelha de leitura normativa que é instrumental na construção da paz em outras localidades se aplica em um processo de paz mais ténue como o do Oriente Médio. É por meio da observação e entrevistas no campo e com oficiais internacionais, assim como por intermédio de documentação primária, que Richmond e Frank buscam uma exploração empírica do processo de construção da paz liberal em seus estudos de caso.

O estudo realizado nesta obra ancora-se firmemente em uma reflexão teórica anterior de Oliver Richmond, ${ }^{1}$ onde este esclarece a moldura teórica em que se alicerça

${ }^{1}$ Richmond, Oliver (2007), The Transformation of Peace. New York: Palgrave Macmillan. 
a paz liberal, mapeando não somente seus principais modos de reflexão acerca da paz, a sua construção enquanto discurso internacional e seus elementos constitutivos, como também as suas variações. Assim, a obra busca a observação empírica destes elementos constitutivos da paz liberal, nomeadamente a democratização, direitos humanos, sociedade civil, a lei e a ordem e a liberalização econômica. A partir disso, Oliver Richmond e Jason Frank buscam observar quais reflexões acerca da paz, designadamente a paz do vencedor, a paz institucional, a paz constitucional e a paz civil, estão presentes no terreno, para justamente perceber em que graduação de paz liberal estes casos se encontram, sendo estas a paz conservadora, a paz ortodoxa e a paz emancipadora.

O discurso da paz do vencedor assenta na paz pelo esmagamento das diferenças. É o argumento de que a paz resultante de uma vitória militar e que se estabeleça através da hegemonia ou dominação é mais duradoura. Já a paz institucional tem a sua base nas tentativas pós Tratado de Vestefália de instituir um contexto normativo e legal no âmbito do qual os Estados multilateralmente concordariam em como se comportar: normas internacionais, organizações internacionais e formas de garantir o cumprimento de tal comportamento. Relativamente à paz constitucional, esta alicerça-se no argumento pós-Iluminista de que a paz se ancora na democracia, no comércio e numa série de valores cosmopolitas onde os indivíduos são o fim em si mesmo e não os meios para outros fins. Por último, a paz civil deriva da noção da ação e participação direta e ativa, e da mobilização social (muitas vezes transnacional) na consecução/defesa de direitos e valores, tendo muitas vezes em mente a justiça social e a emancipação.

Derivadas dessas quatro formas de pensar a paz são delineadas as três graduações da paz liberal. A graduação mais autoritária é representada pelo modo conservador, que é caracterizado por iniciativas de cima para baixo, deixando pouco espaço para a agência local relativamente à construção da paz, podendo inclusive fazer-se uso da coerção, imposição, hegemonia e dominação. Já o modo ortodoxo apresenta uma maior sensibilidade à agência e preocupações locais do que o modo conservador. É um modo caracterizado pela vontade da comunidade internacional liberal em transportar ideias, metodologias e normas para ambientes saídos da conflitualidade violenta. Trata-se de uma iniciativa de cima para baixo e de baixo para cima ao mesmo tempo, uma vez que tenta combinar abordagens à paz baseadas nas necessidades e nos direitos, assim como modos e práticas condicionantes por parte dos doadores, organizações e instituições internacionais, além de ter imbuídos interesses de Estados poderosos. Por último, o modo emancipatório assume uma vertente mais crítica, especialmente em relação aos pontos de coerção, condicionalidades e dependência. Enfatiza, portanto, uma maior relação com os receptores da paz liberal, buscando uma maior agência local e objetivando, em última análise, uma maior justiça social. Inevitavelmente a sua construção passaria por um maior relacionamento, por exemplo, com movimentos sociais locais.

É precisamente com este aparato teórico que os autores chegam ao terreno. Ao examinar a natureza da paz construída no Camboja desde o início dos anos noventa, e sendo esta uma das tentativas mais longas de construção de uma paz liberal, era de esperar que fosse observada uma paz ortodoxa, talvez progressivamente caminhando para uma paz liberal mais emancipatória. Contudo, o que é visto pelos autores é uma paz mais conservadora. É conseguida uma mínima provisão de segurança, o que resulta em uma básica 
ordem e estabilização. Apesar de ter a forma de um Estado liberal, o que é observado é a absorção predatória deste pelas elites, sofrendo a população em geral em grande miséria, falta de democracia, direitos humanos, recursos e lei. São apontadas também muitas das incompatibilidades do modelo externo com a realidade local, principalmente no que toca à cultura e suas formas de organização social e política. Estes fatos, que deixam grandes reticências e preocupações, se se pensar nos avanços e alargamentos obtidos pelos conceitos de paz e de segurança no pós-Guerra Fria. Relativamente ao caso da Bósnia são examinados os efeitos dos Acordos de Paz de Dayton, observando os impactos dos seus elementos de construção da paz liberal no local. É observado, por exemplo, que muitas das causas dos conflitos não foram resolvidas, sendo também perceptível uma clara situação de crise sócio-econômica crônica e frágil segurança. É visível, para os autores, um Estado bastante fragmentado, difuso e algumas vezes não possuindo uma legitimidade local. Sendo claro, portanto, sua fragilidade e dependência relativamente aos atores internacionais, nomeadamente ONU, OSCE, OTAN e UE. Muitas das críticas ao processo de paz na Bósnia recaem no argumento de que os acordos de Dayton institucionalizaram as divisões étnicas, permanecendo a Bósnia dividida, etnicamente polarizada e com agendas políticas separatistas. É também problematizado pelos autores o relacionamento entre a governação por parte da comunidade internacional e as lideranças nacionais/locais, sendo percebida uma grande relutância por parte dos atores internacionais à delegação de poderes. Falha assim uma maior atribuição de poder aos cidadãos na condução de seus assuntos internos, sendo a paz na Bósnia também categorizada pelos autores como conservadora.
No caso do Timor-Leste, o título do capítulo é emblemático: "The Emperor's new clothes?" Apesar de ter sido conquistado um importante passo, a independência formal em relação ao Estado indonésio, o título deve-se ao fato de a paz construída ser apenas limitada e de apresentar todas as aparências de instituições democráticas liberais, sendo inclusive propagado pela comunidade internacional como um caso de sucesso. Contudo, o olhar atento dos autores mostra a falta de substância no Estado timorense, a não transformação das causas raízes do conflito e a exclusão da população local no processo de construção da paz. Assim, apesar de o Estado timorense possuir, para os autores, a aparência de um Estado liberal, não representa a incorporação das vontades políticas e das necessidades da população, sendo com isso produzida também uma paz liberal conservadora.

Relativamente ao Kosovo, os autores examinam como o projeto liberal é suscetível à cooptação local, principalmente quando um grupo possui tanto a habilidade de adotar a linguagem da paz liberal, quanto a de obter grande apoio/credibilidade aos olhos da comunidade internacional. Assim, é focada a consecução dos anseios dos kosovares albaneses, marginalizando as agendas de outros grupos, nomeadamente dos kosovares sérvios. Consequentemente, são enfraquecidos os objetivos pluralistas para o Kosovo, levantando a crítica de que possivelmente a construção da paz liberal, dada a oposição à construção de um Estado kosovar vocalizada pelos Sérvios, encorajou a partição do Kosovo, fato agravado pela recente e muito contestada declaração de independência. Sendo as causas do conflito negligenciadas e levando o pacote liberal à reprodução e acentuação da divisão kosovar, os autores acabam por classificar a paz construída no Kosovo como conservadora. 
No tocante ao Oriente Médio, é observado o processo de Acordos de Paz de Oslo como uma primeira tentativa de introduzir a moldura da paz liberal na localidade. É argumentado que é construída uma paz liberal conservadora que resulta em confrontos linguísticos, culturais, étnicos e religiosos. É observado pelos autores o emprego de um limitado número de instrumentos do modelo da paz liberal, assentando principalmente no tradicional nível da alta diplomacia e em uma abordagem focada em território e segurança. Assim, para Richmond e Frank, é uma construção da paz altamente militarizada, centralizada e discriminatória, privilegiando visivelmente apenas certos grupos, sendo um claro exemplo da paz do vencedor, onde a paz é construída pelas elites militares e políticas. Para os autores, os cinco casos permitem a observação de alguns padrões na construção da paz liberal. Em todos os casos (com exceção do Oriente Médio) foi criado um Estado e foi atingida uma básica, porém frágil, segurança. Em cada um foram criadas instituições democráticas, mas nenhuma funciona de acordo com as intenções da comunidade internacional. Em todos os casos a busca pela economia de mercado foi introduzida e as estratégias de desenvolvimento falharam em reduzir o desemprego, a subsistência e a pobreza. Falharam, assim, em fazer uma grande diferença no dia-a-dia das pessoas. Apesar do grande esforço para o desenvolvimento da sociedade civil, esta ainda permanece um artifício das normas liberais, ao invés de expressões localmente enraizadas de agência social, política ou econômica.

Apesar de encontrado, em todos os casos, um assunto pouco desenvolvido pelos autores, a questão do híbrido local-liberal é um assunto bastante crítico para a reflexão pós-colonial. Este é pouco problematizado, seja para um maior esclarecimento da dinâmica relativamente à atual construção da paz, seja para a reflexão de como poderia ser a construção de uma paz levando em conta a questão do hibridismo. Tal fato, contudo, não diminui em nada a relevância da obra, fazendo com que esta seja essencial para todos aqueles envolvidos com as Relações Internacionais, principalmente para os que têm a paz e a sua construção no cenário internacional como cerne de suas preocupações e reflexões.

\section{Ramon Blanco}

